INVESTIGACIONES

de HISTORIA ECONÓMICA

2005, primavera, número 2. Pp. 9 a 38

\title{
Una estimación del crecimiento económico en la Edad Moderna
}

\section{Simulating early modern economic growth}

\author{
JAN LUITEN VAN ZANDEN \\ International Institute of Social History \\ University of Utrecht
}

\begin{abstract}
RESUMEN
ABSTRACT

Este artículo analiza distintos modos de medir el crecimiento económico de Europa en períodos anteriores a la Revolución Industrial.

Se demuestra que las cifras publicadas por Angus Maddison sobrevaloran probablemente el crecimiento habido entre 1000 y 1820 . A continuación, se desarrolla un modelo para estimar las características del crecimiento a largo plazo, a partir del cual se obtienen series anuales para los países europeos más relevantes, y se discuten sus resultados. Se concluye que el crecimiento fue muy lento entre c. 1450 y c. 1800, con la notable excepción de Inglaterra y Holanda, y que entre c. 1000 y

c. 1450 el PIB por habitante se incrementó probablemente más rápido que en los siglos anteriores a la Revolución Industrial.

PALABRAS CLAVE: Crecimiento económico, Europa, Estimación Códigos JEL: N13, O47, O57

The paper discusses different attempts to measure economic growth in Europe before the Industrial Revolution. It is argued that the figures published by Angus Maddison probably overestimate growth between 1000 and 1820. Next, a method for simulating long-term patterns of growth is presented, and the results of this experiment, i.e. annual time series for the most important European countries, are discussed. It is concluded that growth was very slow between c 1450 and c 1800 -with the notable exceptions of England and the Netherlands- and that between c 1000 and c 1450, GDP per capita increased probably faster than in the centuries before the Industrial Revolution.

KEY WORDS: Economic growth, Europe, Measurement

JEL Codes: N13, O47, O57
\end{abstract}




\section{Introducción ${ }^{1}$}

L

a cuestión de cuánto creció Europa, así como otras zonas, en los siglos anteriores a la Revolución Industrial ha sido objeto de estudio desde principios de 1994) sobre la evolución a largo plazo de la economía británica, en los que se afirmaba que el PIB por habitante en dicho país se había multiplicado por ocho entre el Domesday Book de 1086 y 1800. De hecho, en opinión de este autor, el crecimiento anterior a la Revolución Industrial habría sido casi tan rápido como el que tuvo lugar después de 1780. Posteriormente, diferentes investigaciones — presentadas en el XI Congreso de la Asociación Internacional de Historia Económica (Milán, 1994), en una sesión coordinada por A. Maddison y H. van der Wee- abordaron el mismo tema para diferentes países europeos. En general, las conclusiones de estos estudios eran más conservadoras. Así, el crecimiento entre 1500 y 1800, caso de haber existido, habría sido sustancialmente menor al que tuvo lugar después de dicho período ${ }^{2}$. De hecho, salvo algún repunte alcista, como la "Edad de Oro" holandesa, el crecimiento por habitante habría sido lento (como en el caso de Bélgica) o no se habría producido (Italia, España). Sintetizando los resultados de estos estudios, el PIB por habitante de Europa occidental habría aumentado en promedio, como máximo, alrededor de un 20 por 100 entre c. 1500 y c. 1820. Dado que la cantidad de factor trabajo por habitante se habría incrementado, probablemente, de una manera sustancial, la productividad del trabajo podría haber permanecido constante (Van Zanden, 2001).

En su reciente síntesis sobre el crecimiento de la economía mundial en los últimos dos mil años, Angus Maddison (2001) llega a resultados distintos de los obtenidos en las referidas investigaciones de los años noventa. En su libro The World Economy. A Millennial Perspective, este autor presenta sus propias estimaciones del crecimiento económico europeo entre 1000 y 1820 (e, incluso, para fechas anteriores). Según sus cálculos, el PIB por habitante de Europa occidental se habría triplicado en dicho período. Este resultado sería fruto de la casi duplicación de dicha variable entre 1000 y 1500, y de un incremento de un 56 por 100 de la misma en los tres siglos anteriores a la Revolución Industrial. Giovanni Federico, no obstante, en su exhaustiva reseña del libro de Maddison (Federico, 2002), señala algunos puntos débiles de

1 Agradezco a los participantes en los seminarios de Utrecht, Siena, Florencia (EUI), Nápoles y Tuebingen, y en particular a Joerg Baten, Bas van Bavel, Giovanni Federico, Oscar Gelderblom, Angus Maddison y Paolo Malanima, sus comentarios a versiones anteriores de este artículo, y a Bas van Leeuwen por su ayuda con el modelo de regresión. Estoy en deuda, asimismo, con los tres informantes anónimos de Investigaciones de Historia Económica. Obviamente, todos los errores son de mi exclusiva responsabilidad.

2 Blomme y Van der Wee (1994), Malanima (1994), Yun (1994) y Van Zanden (1993). 
tales estimaciones: unos niveles de PIB por habitante para la Edad Media demasiado bajos (justo por encima de los niveles de subsistencia), y unas tasas de crecimiento entre 1500 y 1800 que parecen poco consistentes con otras estimaciones alternativas del crecimiento de la productividad del trabajo en la agricultura.

En este artículo trato diversas cuestiones sobre el crecimiento económico en la época moderna. En primer lugar, analizo la relación —cambiante- entre crecimiento y cambio estructural, llegando a la conclusión de que las estimaciones de Maddison - y también las de Snooks- no son realistas. A continuación, desarrollo un nuevo método para estimar series anuales que representen la evolución del PIB europeo en el largo plazo. Para ello, he utilizado estimaciones del PIB por habitante consideradas de referencia entre los especialistas, así como información sobre la evolución de los salarios reales y el cambio estructural —cambios en la distribución sectorial de la población activa - en la economía europea antes de 1800. Finalmente, discuto una de las cuestiones abordadas por Maddison al realizar sus estimaciones del PIB europeo, la comparación con China. Este contraste está obviamente relacionado con el debate, iniciado por K. Pomeranz (2000) y R. B. Wong (1997), sobre el progreso y la posición relativa de las economías china y europea en el siglo XVIII. Según los resultados de Maddison, mientras que el PIB per capita chino superaba al europeo hacia el año 1000, ocho siglos después el primero sólo representaba la mitad del segundo (y tan sólo un tercio del británico). Dado que este autor sostiene que el PIB por habitante del país asiático no descendió en dicho lapso, asume, necesariamente, que el crecimiento europeo fue muy rápido. Este supuesto, a mi juicio, ayuda a explicar el hecho de que Maddison tienda a sobrestimar el crecimiento europeo anterior a 1820. Para contrastar la visión alternativa del crecimiento de Europa que se presenta en este artículo, se tiene en cuenta este problema y, por ello, se vuelve sobre el debate existente acerca de los niveles relativos de PIB por habitante anteriores a la Revolución Industrial. No obstante, primero centraremos nuestra atención en Europa.

\section{Crecimiento económico en la Edad Moderna y cambio estructural}

La relación entre crecimiento económico y cambio estructural —es decir, en términos relativos, el declive de la agricultura y el desarrollo de la industria y los servicios como fuentes de empleo y producto- ha sido un tema de estudio frecuente desde las contribuciones pioneras de C. Clark (1940) y S. Kuznets (1966). Ambos autores identificaron pautas de cambio similares entre los países que se industrializaron en el siglo XIX y aquéllos que estaban haciéndolo en el XX. Posteriormente, H. B. Chenery y M. Syrquin (1975) modelizaron de forma sistemática la relación entre niveles 
de cambio estructural y diversas variables macroeconómicas, distinguiendo asimismo diferentes modelos de transformación, en función del tamaño del país y su especialización exportadora (productos primarios o industriales). No obstante, se ha prestado escasa atención a cómo estos modelos podrían modificarse con el paso del tiempo.

N. Crafts (1985) aplicó esta metodología a la Europa del siglo XIX a fin de entender las particularidades de la industrialización británica. Los resultados obtenidos mostraban que el caso de este país había sido excepcional, dado que el nivel de cambio estructural fue mucho mayor que el esperado según el modelo tradicionalmente difundido de la industrialización europea en el siglo XIX (el "modelo europeo"). Según tal comparación, este autor identificaba como principales características de la Revolución Industrial británica un "bajo crecimiento de los ingresos y [un] rápido cambio estructural". Así, la participación de la agricultura en el empleo y el producto cayó mucho más rápido de lo esperado según la pauta de la Europa del Ochocientos (Crafts, 1985, p. 61). En 1800, por ejemplo, el PIB por habitante era, según Crafts, de 427 dólares de 1970, el cual, según el modelo europeo, se correspondería con una participación del 62,3 por 100 de la fuerza de trabajo en la agricultura, cuando ésta era en realidad de tan sólo un 39,9 por 100 (Crafts, 1985, p. 62).

Crafts interpretó esta pauta de cambio estructural rápido y de crecimiento lento como parte de la excepcionalidad británica en este período. Sin embargo, ensayos similares con datos sobre la evolución de la economía holandesa en el siglo XIX, realizados por A. Burger (1996), y Van Zanden y Van Riel (2004), detectan esta misma "excepcionalidad". Así, la economía holandesa a principios del siglo XIX también presentaba una agricultura más pequeña que la correspondiente a la pauta europea. Burger (1996), por ejemplo, encontró que la contribución de la agricultura al PIB en 1810 era del 31 por 100, mientras que la media europea era del 45 por 100, una diferencia similar a la calculada por Crafts. Sólo a partir de 1870 esta brecha desaparecía y Holanda convergía con la media europea.

El hecho de que sean precisamente estos dos países los que presentan ese modelo "excepcional" difícilmente puede considerarse fruto de una coincidencia. Ambos son ejemplos exitosos de desarrollo económico en la Edad Moderna, y presentaban, de hecho, las mayores cifras europeas de PIB por habitante a principios del siglo XIX. El precio que se pagó por este crecimiento precoz fue una transformación aún más radical de la estructura productiva de la economía. Esto sugiere que la relación entre crecimiento del PIB y cambio estructural era distinta antes de, aproximadamente, 1820 que en los siglos posteriores a la Revolución Industrial.

Esta hipótesis puede verificarse fácilmente comparando varias trayectorias de cambio estructural. El Gráfico 1 combina dos "modelos" utilizados por Crafts -el europeo del siglo XIX y el mundial del período 1950-1970, deducido a partir de Chenery y Syrquin (1975) — con las últimas observaciones disponibles para la Europa de 


\section{GRÁFICO 1}

RELACIÓN ENTRE PIB POR HABITANTE Y PARTICIPACIÓN DE LA AGRICULTURA EN EL EMPLEO

(PIB por habitante británico en 1820=100)

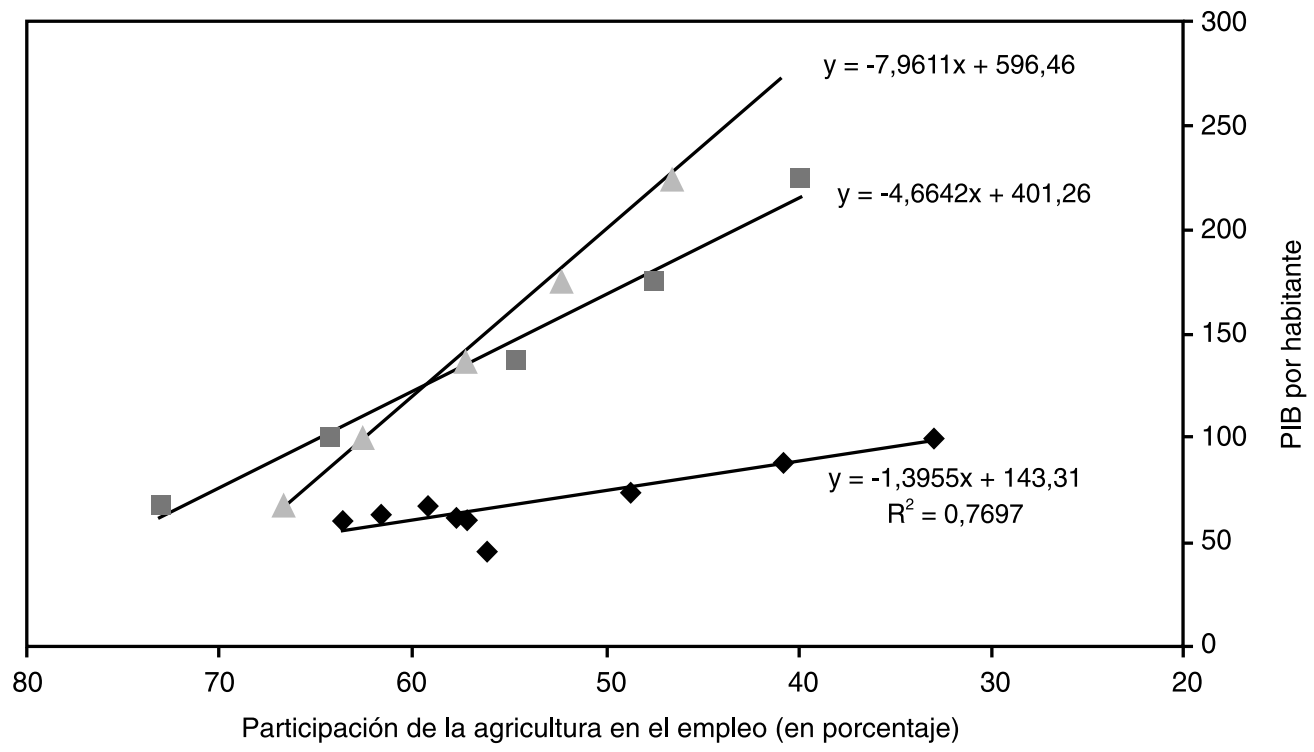

comienzos del siglo XIX $(1820)^{3}$. Las diferencias son patentes. En el último caso, la curva obtenida presenta una menor pendiente, mostrando que, con anterioridad a 1820, un descenso en el porcentaje de población dedicada al sector primario se correspondería con un crecimiento del PIB por habitante sustancialmente menor al que se produciría más tarde. Mientras que, antes de 1820, una reducción del empleo en la agricultura del 50 por 100 (del 66 al 33 por 100) supondría un incremento aproximado del PIB por habitante de un 90 por 100, durante el siglo XIX, ese mismo cambio en el empleo vendría acompañado de un aumento en el PIB per capita del 165 por 100, aumento que sería aún mayor para 1950-1970 (del 369 por 100) ${ }^{4}$.

Los datos de PIB para 1820 provienen de Maddison (1995), los cuales he preferido a las estimaciones que para la misma fecha se recogen en Maddison (2001). Esto se debe a que, en las últimas, las cifras de PIB por habitante para Holanda en 1820 son superiores a las británicas, hecho que considero poco probable. Las participaciones de la agricultura en el empleo total provienen de Allen (2000a).

4 Los resultados obtenidos difieren levemente cuando se aplica una escala logarítmica en lugar de una aproximación lineal. El gráfico, obviamente, no se ve apenas modificado. 
Esta relación variable entre cambio estructural y crecimiento por habitante es de por sí un hallazgo relevante, pero su discusión y análisis se encuentra, sin embargo, fuera del alcance de este trabajo. Aquí, dicha relación se utiliza - junto con una serie de estimaciones de la evolución a largo plazo de la estructura del empleo en los países europeos entre 1500 y 1800 - para contrastar la validez de los cálculos efectuados por Maddison, así como por otros autores. Asimismo, se comparan tres evaluaciones distintas del PIB por habitante: la muestra para 1820 de nueve países europeos (proveniente de Maddison, 1995); las estimaciones de Maddison para esos mismos países entre 1500 y 1820 (Maddison, 2001); y las mías propias (Van Zanden, 2001). Estas últimas son una síntesis de los trabajos realizados por distintos historiadores económicos (Malanima, Blomme y Van der Wee, Yun, y Van Zanden), a las que he añadido las cifras para Polonia del trabajo de Topolski y Wyczanski (1982) y las de Inglaterra del de Overton y Campbell (1997). Todas las series han sido normalizadas estableciéndose como base 100 el PIB por habitante de Gran Bretaña en 1820. Las relaciones estimadas entre PIB por habitante y participación de la agricultura (Agr.) son las siguientes (entre paréntesis los errores estándar) ${ }^{5}$ :

- Para las estimaciones en 1820:

- Para las cifras de Maddison, 1500-1820:

- Para las cifras de Van Zanden, 1500-1820:
$143-1,40$ * Agr. $\left(\mathrm{R}^{2}=0,770\right)$

$(15,53)(0,288)$

$173-1,95$ * $\operatorname{Agr}\left(\mathrm{R}^{2}=0,703\right)$

$(18,31)(0,294)$

$136-1,24$ * Agr $\left(\mathrm{R}^{2}=0,573\right)$

$(10,80)(0,151)$

Resulta evidente que Maddison supone una relación entre cambio estructural y crecimiento del PIB más fuerte que la que se deriva del corte transversal de 1820, aunque el coeficiente estimado a partir de sus datos $(1,95)$ aún se encuentre dentro del intervalo de confianza definido por el doble del error estándar $(1,95<1,968)$. El coeficiente que se deriva de las estimaciones de Van Zanden es más parecido al del corte transversal de 1820 e, incluso, el que sea algo menor acrecienta probablemente su validez, dado que esta relación entre crecimiento y cambio estructural tiende a reforzarse con el transcurso del tiempo (Gráfico 1). Según las estimaciones de Maddison, una caída de la fuerza de trabajo dedicada a la agricultura del 66 al 33 por 100 es compatible con un crecimiento del 144 por 100 del PIB por habitante, frente al 90 por 100 que se derivaría de los datos de 1820 y al 77 por 100 que resultaría de las estimaciones efectuadas por Van Zanden. Resulta evidente, pues, que estas últimas se acercan más a los datos del corte transversal de 1820.

5 La estructura de la fuerza de trabajo se toma de Allen (2000a). De nuevo, las trayectorias logarítmicas presentan resultados similares a las lineales. He escogido las últimas por su claridad y por la facilidad con que se detecta el impacto sobre el PIB por habitante de una reducción del 50 por 100 de la participación de la agricultura en el empleo total. 


\section{GRÁFICO 2}

RELACIÓN ENTRE PIB POR HABITANTE Y PARTICIPACIÓN DE LA AGRICULTURA EN EL EMPLEO, EUROPA 1500-1800

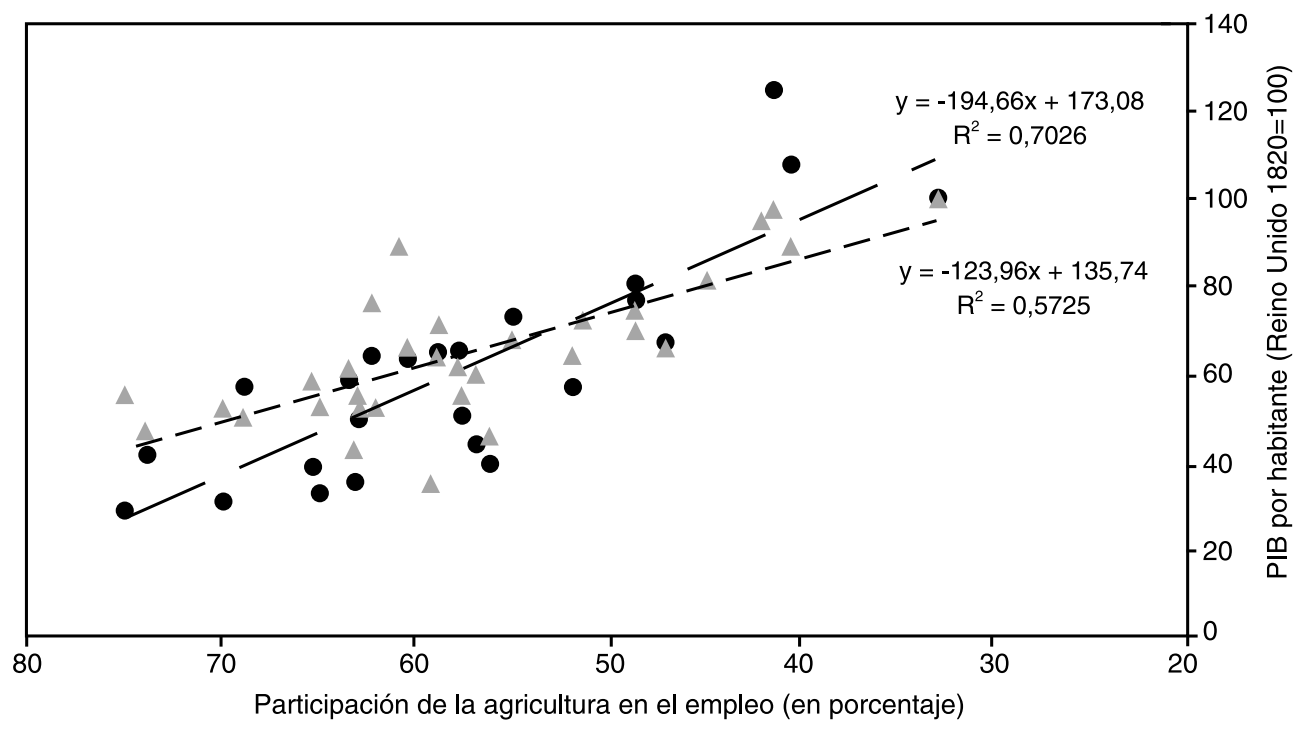

Maddison $\quad \Delta$ Van Zanden $\longrightarrow$ Lineal (Maddison) -- Lineal (Van Zanden)

El Gráfico 2 recoge las dos estimaciones objeto de estudio. La primera impresión es que la serie de Maddison sobrevalora el crecimiento del PIB por habitante. Esto mismo puede concluirse de la comparación de sus cifras con los resultados de estudios sobre diferentes países. Por ejemplo, Yun (1994) calcula que el PIB por habitante en España, en concreto en la Corona de Castilla, a principios del siglo XIX, no era mayor - quizá fuese, incluso, algo menor-que el del último cuarto del siglo XVI. Las cifras de Maddison para España, por el contrario, muestran un crecimiento de esta variable de más del 50 por 100 entre 1500 y 1820 (y del 18 por 100 entre 1600 y 1820 $)^{6}$. Problemas similares surgen también al comparar los datos de Maddison (2001) con las estimaciones de Malanima para la Italia septentrional o las mías para Holanda (Van Zanden, 1987, 1992 y 1993). Mientras que, según mis cálculos, el PIB por habitante en Holanda se incrementó, como máximo, un 50 por 100 entre 1500 y

6 Carreras, en su reciente síntesis de los estudios sobre el crecimiento económico en la España moderna, llega a una conclusión más próxima a la de Yun que a la de Maddison. Carreras (2003). 
1820, de las estimaciones de Maddison se infiere que dicho crecimiento sería del 141 por 100. La diferencia entre ambas cifras se debe, fundamentalmente, a los cálculos de este autor para antes de 1580. La reconstrucción de las cuentas nacionales de Holanda a principios del siglo XVI, que realicé tras la publicación de mi artículo de 2001, insisten, de nuevo, en el limitado crecimiento que tuvo lugar entre 1500 y 1800. La estimación más optimista que obtuve para el crecimiento del PIB por habitante holandés, en dicho período, consistió en un incremento del 34 al 57 por 100. No obstante, el crecimiento fuera de Holanda podría haber sido más rápido (Van Zanden, 2002a).

Las estimaciones de Maddison para el Reino Unido son una historia diferente. Maddison rechaza los cálculos de Snooks, muy discutidos también por otros autores. Quizá la crítica más devastadora que han recibido sea la de B. Campbell, quien, basándose en una exhaustiva reconstrucción de la producción agrícola durante la Edad Media (en 1086 y 1300), muestra que las cifras de Snooks son excesivamente bajas. Según Campbell, el PIB por habitante calculado por Snooks habría sido menor que la producción agrícola necesaria para alimentar a la población inglesa (Campbell, 2000, pp. 406-410). En un trabajo anterior, he usado las estimaciones de Overton y Campbell (1997) de la producción agrícola inglesa entre 1086 y 1871, con el fin de extender hacia atrás la serie de PIB por habitante de Crafts, que empieza en 1688 (Van Zanden, 2001, pp. 74-75). A este respecto, Maddison, tras analizar las diferentes interpretaciones existentes del crecimiento anterior a 1700, afirma, no obstante, que "la tasa [de incremento] del ingreso por habitante de Crafts-Harley para 1700-1801 era válida para 1500-1700" (Maddison, 2001, p. 246).

Para la Europa del Este, Maddison supone que el PIB por habitante aumentó alrededor de un 37 por 100 entre 1500 y 1800. En mis series, he incluido únicamente Polonia, utilizando las estimaciones de Topolski y Wyczanski (1982), las cuales, además de incluir diferentes supuestos sobre lo que ocurrió con el producto no agrícola, muestran que el producto agrícola por habitante cayó alrededor de un tercio entre 1570 y 1800. Esto dio como resultado un largo período de estancamiento del PIB per capita polaco. Por último, la nueva investigación de O. Krantz (2004) sobre la evolución a largo plazo del PIB sueco en la Edad Moderna, también corrobora las interpretaciones más pesimistas. Este autor resume sus cálculos para 1571 como sigue: "A pesar de los márgenes de incertidumbre, podría inferirse que el PIB por habitante fue prácticamente el mismo en el siglo XVI que hacia 1800. Además, Suecia, al igual que otros países de la periferia, se caracterizó por un estancamiento entre los siglos XVI y XIX" (Krantz, 2004, p. 120). Esto contradice de nuevo las estimaciones de Maddison (2001), las cuales muestran un incremento del PIB por habitante en Suecia de un 45 por 100 entre 1600 y 1820 - o un 73 por 100 entre 1500 y 1820 —.

En conclusión, existen dos razones para no utilizar las estimaciones de Maddison sobre el crecimiento europeo en la Edad Moderna: por un lado, son inconsisten- 
tes con la relación entre crecimiento y cambio estructural que parece haber existido antes del siglo XIX; y, por otro, no concuerdan con la mayor parte de las investigaciones realizadas en los últimos años. Por estas razones, prefiero utilizar mis propias series, basadas en la literatura reciente anteriormente reseñada, y que no cuentan con las debilidades que presentan las estimaciones de Maddison.

\section{Una estimación del crecimiento anterior a $\mathbf{1 8 0 0}$}

El Gráfico 2 muestra que existió una relación entre cambio estructural y crecimiento económico en la Europa de la Edad Moderna, pero también que su dispersión en el seno de la tendencia estimada fue muy amplia. Un $R^{2}$ de 0,57 o ligeramente superior $(0,60)$, cuando se trata de una estimación logarítmica, no resulta muy elocuente. Una manera de mejorar el ajuste del modelo es incorporando otros índices de nivel de desarrollo de la economía. Gracias a la investigación de R. Allen (2001) tenemos disponible un conjunto de estimaciones comparables de salarios reales de cerca de una docena de ciudades europeas para la Edad Moderna. La mayor parte de los datos corresponden a las capitales - $\mathrm{u}$ otra ciudad importante- de los países incluidos en la muestra. Para algunas ciudades (Londres y Florencia), la serie de salarios reales se inicia a principios del siglo XIV, pero la mayoría de las series comienzan en los siglos XV o XVI. Resulta evidente la existencia de una relación entre salario real y PIB por habitante, aunque dicha relación podría modificarse a lo largo del tiempo — con cambios en la distribución del ingreso y / o la estructura de la economía - y variar entre las distintas zonas europeas.

El enfoque ecléctico escogido en este trabajo explica la variación del PIB por habitante en Europa entre 1500 y 1800, a partir de los datos de Van Zanden, en función de dos variables independientes: los salarios reales de los trabajadores no cualificados (en la capital del país) y el nivel de transformación estructural de las economías objeto de estudio $^{7}$. Intuitivamente, estas dos variables representan dos partes de la economía:

7 Los datos han sido modificados de la siguiente manera: 1) Ha sido incluido el dato para España en 1500, recogido de Carreras (2003), y, de acuerdo con este mismo trabajo, se han revisado el resto de las estimaciones para dicho país; 2) la referencia de 1820, tomada de Maddison (2001), es proyectada hacia atrás hasta 1800 utilizando las tasas medias de crecimiento en el período 1700-1820 (esto lleva, no obstante, a correcciones marginales en las posiciones relativas de los países); 3) las estimaciones de Maddison (2001) para el Reino Unido han sido transformadas en estimaciones para Inglaterra y Gales de acuerdo con Maddison (2001), p. 247; 4) los datos incluyen dos estimaciones para el período anterior a 1500: Italia en 1450 e Inglaterra en 1380; por tanto, el análisis de datos de panel está descompensado. Nótese, asimismo, que casi todas las estimaciones de Van Zanden se basan en cálculos del producto, por lo que son independientes de los salarios reales utilizados en la regresión. La única excepción a esta regla son las series proporcionadas por Malanima (1994), quien utiliza estimaciones de salarios reales junto con otros indicadores del producto. 
los salarios reales obviamente recogen el ingreso de los trabajadores, pero también están relacionados con la productividad del trabajo en la agricultura (Allen, 2000a). La participación de la agricultura en el empleo es, a su vez, un índice de cambio estructural, y está inversamente relacionada con el grado de industrialización y urbanización. En otro trabajo he demostrado la existencia de una fuerte conexión entre cambio estructural en la economía y desigualdad en el ingreso durante la Edad Moderna (Van Zanden, 1995). La urbanización y la industrialización se tradujeron, especialmente en el caso de Holanda, en un fuerte incremento del grado de concentración de las rentas del capital en las ciudades. Podemos suponer, por tanto, que el porcentaje de la fuerza de trabajo dedicada a la agricultura guarda una relación inversa con las rentas de los no asalariados. Luego puede esperarse una correlación positiva entre salarios reales y PIB por habitante, y una negativa entre participación de la agricultura en el empleo y PIB per capita.

El Cuadro 1 recoge los resultados de un análisis de regresión con datos de panel, que explica la evolución del logaritmo del PIB por habitante según tres variables independientes: Logparticipación, el logaritmo de la participación de la agricultura en el empleo; Logsalariosreales, el logaritmo de los salarios reales; y G2...G6, variables dummies que recogen si es, o no, Inglaterra (G1 es Inglaterra, utilizado como el estándar). Los resultados son bastante satisfactorios: las variables presentan los signos esperados (positivo para los salarios reales y negativo para la participación de la agricultura), las variables dummies-país tienen un impacto mucho menor - con la excepción de Italia, donde el PIB por habitante es significativamente mayor que el esperado según los supuestos del modelo-, y el ajuste general es bastante bueno, aunque el número de observaciones es muy limitado ${ }^{8}$.

El siguiente paso consiste en utilizar este modelo para estimar series anuales de PIB por habitante en diversos países europeos, teniendo en cuenta:

1) Las estimaciones anuales de salarios reales de los trabajadores en las capitales de los países incluidos en la muestra9.

2) Las estimaciones de la participación de la agricultura en el empleo para 1300 (sólo para Inglaterra e Italia), 1400, 1500, 1600, 1700, 1750 y 1800, incluidas en Allen (2000a), que han sido convertidas en series anuales por interpolación simple. En algún caso, donde los cálculos de De Vries (1984a, p. 39) sobre el grado de urbanización entre 1500 y 1800 indicaban que se había tratado de un proceso discontinuo entre los cortes temporales escogidos (más rápido en la primera mitad del siglo que en la segunda, o viceversa), he adaptado la interpolación a dicho comportamiento.

8 En el Apéndice se recoge un modelo alternativo en el que se han incluido variables dummies-tiempo.

9 Austria: Viena; Inglaterra: Londres; Holanda: Ámsterdam; Alemania: Augsburgo (Estrasburgo para algunos años); Bélgica: Amberes; Italia: Florencia (y Milán); España: Madrid (Sevilla para algunos años); Polonia: Cracovia. 


\section{CUADRO 1}

EXPLICACIÓN DE LA VARIACIÓN DEL PIB POR HABITANTE EN EUROPA, 1500-1800

(a partir de datos de Van Zanden)

\begin{tabular}{lcccc}
\hline & Coeficiente & Error estándar & Valor de t & Prob. de t \\
\hline Logparticipación & $-0,857$ & 0,121 & $-7,10$ & 0,000 \\
Logsalariosreales & 0,219 & 0,081 & 2,71 & 0,012 \\
Constante & 3,224 & 0,177 & 18,30 & 0,000 \\
G2 & 0,189 & 0,045 & 4,17 & 0,000 \\
G3 & $-0,100$ & 0,055 & $-1,84$ & 0,078 \\
G4 & 0,294 & 0,082 & 3,60 & 0,001 \\
G5 & $-0,092$ & 0,054 & $-1,72$ & 0,097 \\
G6 & $-0,127$ & 0,109 & $-1,17$ & 0,252 \\
\hline
\end{tabular}

G2 = Holanda, G3 = Bélgica, G4 = Italia, G5 = España, G6 = Polonia

$\mathrm{R}^{2} 0,846$

RSS 0,440

TSS 2,86

$N^{\circ}$ de observaciones: $33 \quad N^{\circ}$ de parámetros: 8

Así, es posible utilizar la ecuación del Cuadro 1 para estimar el PIB anual por habitante. Los cambios anuales en dicha variable, sin embargo, no deberían interpretarse en un sentido estricto ${ }^{10}$; el objetivo del trabajo es el análisis de las características a largo plazo del cambio económico, y las fluctuaciones anuales son, en gran medida, producto del método utilizado. En la discusión de los resultados del modelo, por tanto, fijaré mi atención en los cambios que se aprecian en el largo plazo ${ }^{11}$.

10 No obstante, estos datos son válidos, aunque sólo sea parcialmente, dado que son fruto de las variaciones anuales de los salarios reales, las cuales reflejan — teniendo en cuenta la rigidez de los salarios nominaleslas fluctuaciones de los precios, que a su vez se debían a la existencia de buenas o malas cosechas. Puesto que el PIB europeo estaba dominado por el sector agrícola, las variaciones del volumen anual de las cosechas podrían haber tenido un impacto importante en el PIB por habitante.

11 Para los países incluidos en las series de Van Zanden, las dummies-país del Cuadro 1 también han sido utilizadas. Para los países que no aparecen en dichas series (Alemania, Francia y Austria), pero para los cuales existen estimaciones del resto de las variables, también he calculado el PIB por habitante, esta vez sin las variables dummies. 


\section{GRÁFICO 3}

PIB POR HABITANTE DE INGLATERRA, ITALIA, HOLANDA Y POLONIA, 1500-1800

(Inglaterra y Gales en $1800=100$ )

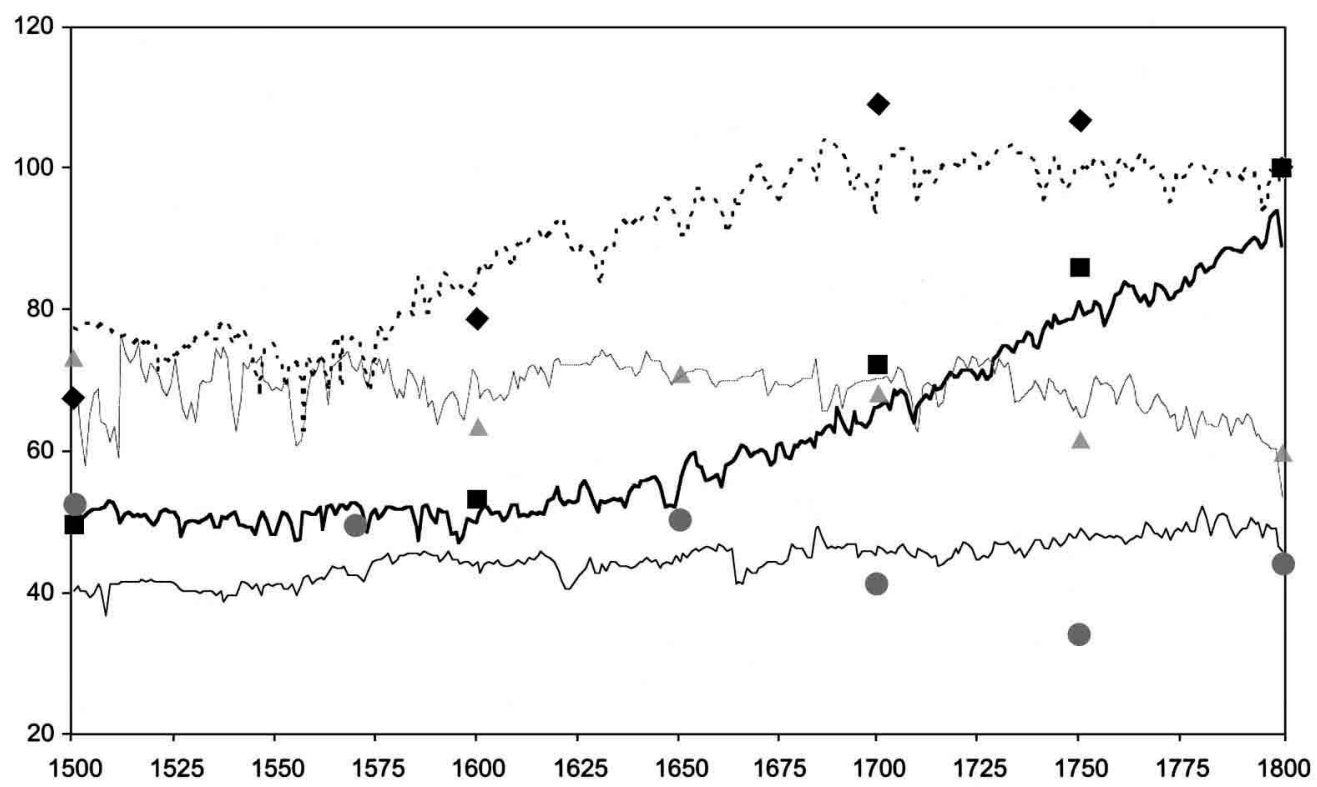

\begin{tabular}{|c|c|c|}
\hline - Inglaterra & Italia & ...... Holanda \\
\hline Polonia & Inglaterra/Van Zanden & Italia/Van Zanden \\
\hline Holanda/Van Zanden & Polonia/Van Zanden & \\
\hline
\end{tabular}

El Gráfico 3 recoge las estimaciones para el período 1500-1800 de los países que he considerado más interesantes. Las series continuas son el resultado de aplicar el modelo especificado, mientras que los puntos representan las estimaciones originales en las que éste se ha basado (los datos de Van Zanden).

De acuerdo con esta reconstrucción, Polonia creció tan sólo débilmente durante los tres siglos considerados. Dicho crecimiento, además, se explica en su totalidad por el hecho de que Allen estima un cierto cambio estructural en dicha economía en el largo plazo, como resultado de la reducción de la fuerza de trabajo dedicada a la agricultura — del 75 por 100 en 1500, al 56 por 100 en 1800 - Las estimaciones puntuales originales son más pesimistas: el PIB por habitante, en realidad, habría disminuido entre un 10 y un 20 por 100 en esas tres centurias. 
Por el contrario, ambas aproximaciones ofrecen similares resultados para Italia (en concreto para el norte del país): estancamiento del PIB por habitante en un nivel relativamente alto y cierta disminución sólo durante el siglo XVIII, fruto de la caída de los salarios reales. El caso holandés muestra una posición relativa alta en 1500, a la que sigue un lento, pero continuo, descenso durante los tres primeros cuartos del siglo XVI. Entre los años ochenta de este siglo y los setenta del siguiente - la "Edad de Oro" holandesa-, el PIB por habitante de dicho país aumentó rápidamente, crecimiento al que siguió una larga etapa de estabilidad en un nivel alto. Esta trayectoria es consistente con la literatura al respecto (De Vries y Van der Woude, 1997); pero, en cambio, resulta significativo que las cifras estimadas no recojan completamente el supuesto crecimiento acelerado del PIB holandés durante la primera etapa de expansión, entre 1580 y 1650 (para fechas posteriores, las dos estimaciones convergen de nuevo).

Posiblemente, la trayectoria más interesante sea la británica. Ambas series muestran una estabilidad a un nivel no especialmente alto entre 1500 y los años veinte del siglo XVII, que es seguida por un take off hacia un crecimiento económico sostenido desde las décadas de los veinte y treinta en adelante, proceso que continúa durante el resto del período estudiado (y, como es obvio, también posteriormente). Entre los años veinte del siglo XVII y 1800, el PIB por habitante prácticamente se duplicó, algo que resulta más llamativo, incluso, que el crecimiento del PIB por habitante holandés durante el siglo XVII —el cual fue "sólo" de un 40 por 100, si tomamos 1500 como punto de partida-. De nuevo, esta evolución coincide con las estimaciones disponibles y la literatura más reciente. Wrigley (2000), en un estudio de hace pocos años, fecha el inicio de la "divergencia" de la economía inglesa en el siglo XVII, aunque sin poder especificar la cronología de ese proceso $^{12}$.

Menos espectaculares son las trayectorias de otros países (las estimaciones para Austria, muy similares a las de Alemania, no se incluyen en el Gráfico 4). Posiblemente, lo más llamativo es la caída en el largo plazo de España. Sin embargo, el modelo no recoge el incremento del PIB por habitante que, de acuerdo con Yun (1994) y Carreras (2003), tuvo lugar en el siglo XVIII. Bélgica presenta una evolución positiva durante el siglo XVI, a la que sigue un período de estancamiento en el XVII, y un leve descenso durante el XVIII. Esta aminoración del PIB belga desde, aproximadamente, 1700, contrasta, no obstante, con la visión tradicional (que se sintetiza en Blomme y Van der Wee, 1994). Francia y Alemania parecen intercambiarse sus posiciones: en el siglo XVI, el PIB por habitante alemán era 


\section{GRÁFICO 4}

PIB POR HABITANTE EN FRANCIA, ALEMANIA, BÉLGICA Y ESPAÑA, 1500-1800

(Inglaterra en $1800=100$ )

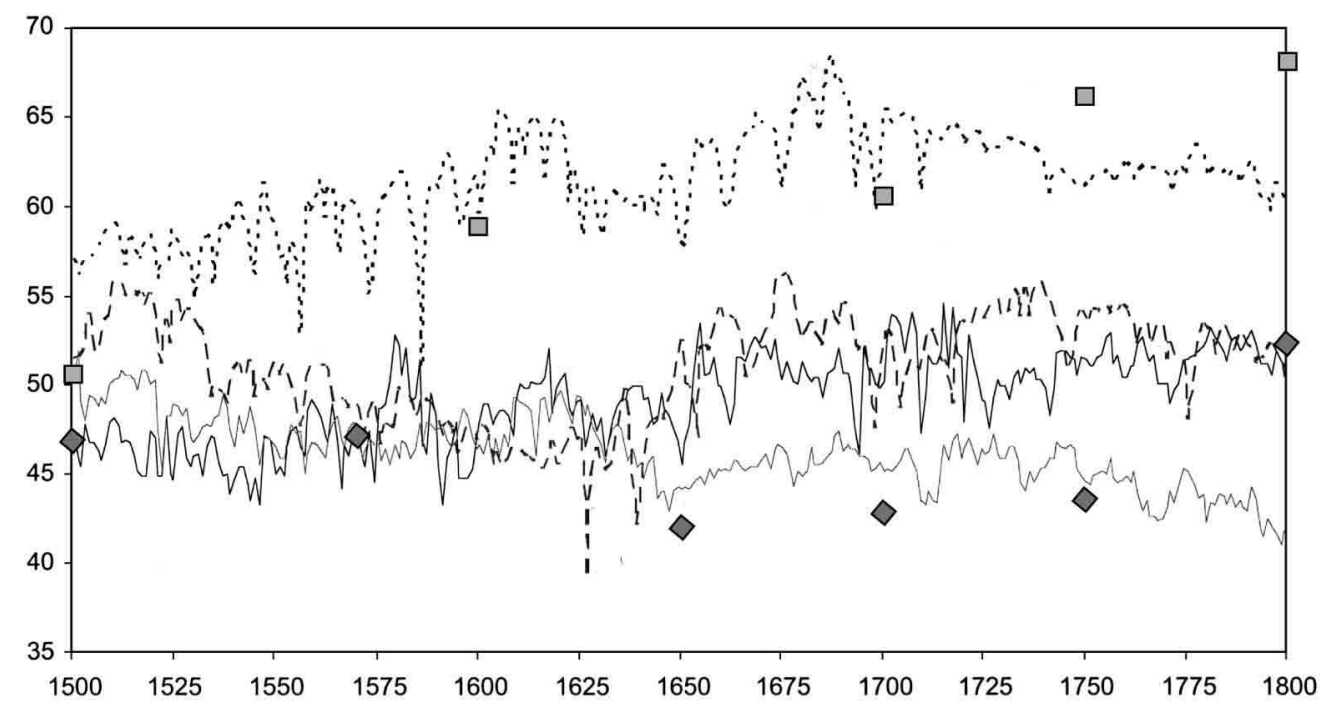

\begin{tabular}{|c|c|c|}
\hline - Francia & - - - Alemania & ......Bélgica \\
\hline España & Bélgica/Van Zanden & España/Van Zanden \\
\hline
\end{tabular}

superior al francés, pero la economía alemana no parece hacerlo muy bien entre 1560 y 1650 (los peores años son los comprendidos entre 1618 y 1648, algo que no sorprende), mientras que Francia avanza posiciones paulatinamente durante el siglo XVII. Las diferencias entre los dos países (y con Austria) son, no obstante, reducidas.

A partir de las estimaciones del PIB por habitante y de la población total de los nueve países europeos, es posible calcular el PIB per capita europeo entre 1500 y 1800 (Gráfico 5). Téngase en cuenta que estas estimaciones no incluyen los países nórdicos, Portugal, Suiza, Irlanda, Gales y Escocia. Sí recogen datos para Polonia y Austria - que también abarca Checoslovaquia y Hungría-. El Gráfico 5 muestra una leve disminución durante el siglo XVI (caída de los salarios reales, y dificultades económicas en Holanda y Alemania), a la que sigue una larga etapa de modesto crecimiento en el XVII hasta los años treinta del siglo XVIII, impulsa- 


\section{GRÁFICO 5}

PIB POR HABITANTE Y POBLACIÓN DE EUROPA, 1500-1800

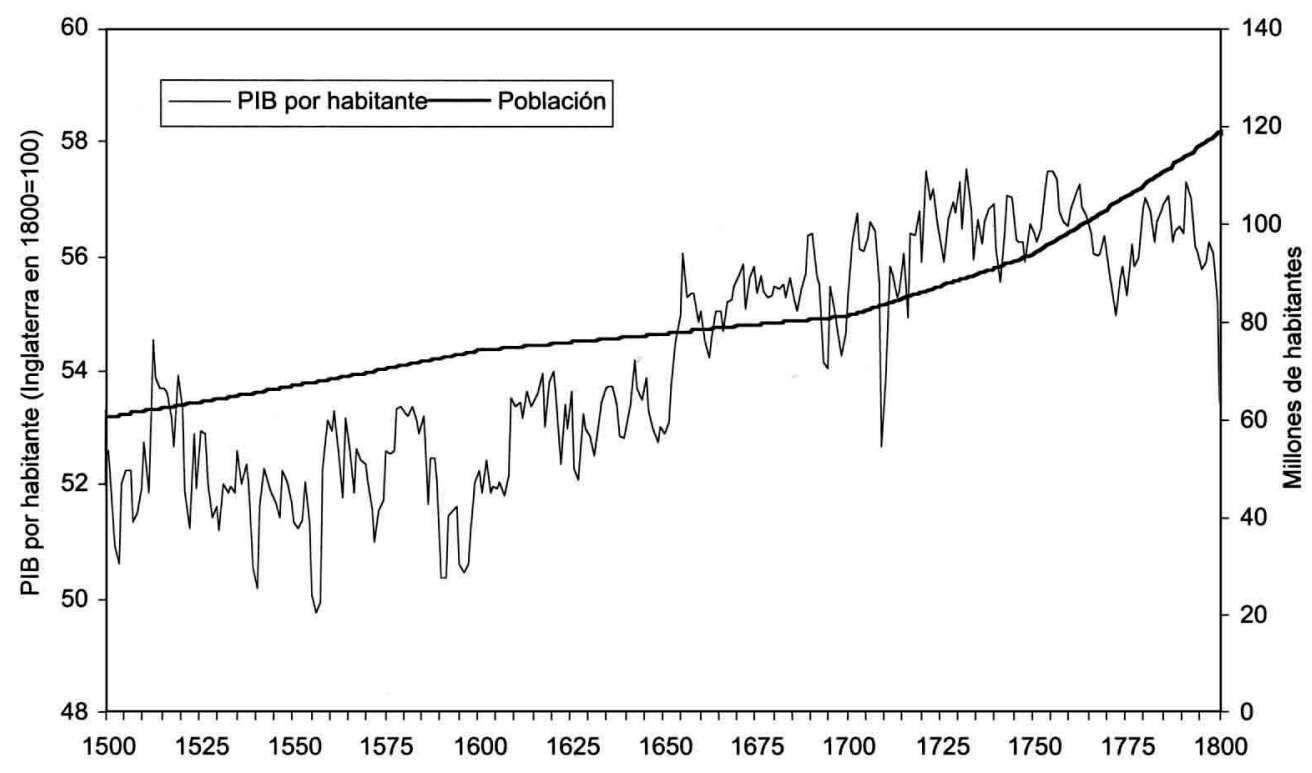

do por la expansión de la economía holandesa, y, posteriormente, por el dinamismo inglés. A lo largo de la segunda mitad del Setecientos, la expansión inglesa se ve contrarrestada por la disminución de los niveles del PIB en la mayoría de los países, en especial en Italia. El crecimiento a largo plazo no es muy elocuente: el PIB por habitante se incrementó menos de un 10 por 100 en el transcurso de los tres siglos que van de 1500 a 1800. El Gráfico 5 también incluye la evolución de la población europea. Se puede observar que el aumento del PIB por habitante es relativamente reducido en momentos de rápido crecimiento de la población (el siglo XVI y la segunda mitad del XVIII) y, por el contrario, relativamente rápido durante la "depresión" del siglo XVII, cuando la población aumentaba a un ritmo lento. Esta conexión maltusiana es menos evidente si las estimaciones se analizan a un nivel más desagregado, dado que el incremento poblacional es más rápido en las zonas europeas más dinámicas (Inglaterra y Holanda). 


\section{Un milenio de crecimiento}

¿Es aplicable el modelo anterior también a la Edad Media? Téngase en cuenta que se basa en 33 estimaciones puntuales del PIB por habitante en seis países europeos, para los que contamos, sólo en dos casos, con datos anteriores a 1500 (Inglaterra en 1380 e Italia en 1450). En la primera especificación no se incluían en el modelo variables dummies-tiempo. Según el modelo alternativo recogido en el Apéndice, donde sí se introducen este tipo de variables, éstas presentan coeficientes negativos, lo que implica que el mismo nivel de cambio estructural del siglo XVI o del XVIII, conduce a un incremento menor del PIB por habitante en el XV. Este resultado es consistente con lo que veíamos en el apartado 2 para los siglos XIX y XX, cuando tuvo lugar una variación similar en la relación entre cambio estructural y PIB por habitante. Por tanto, si el modelo se aplica a períodos anteriores a 1500, el crecimiento probablemente estará sobreestimado. Aun así, puede ser útil dilucidar cuáles son las implicaciones del modelo para la trayectoria — estimada - del crecimiento en el largo plazo.

Para dos países, Inglaterra e Italia, disponemos de series de salarios y estimaciones de la distribución sectorial de la fuerza de trabajo en el período 1300-1500. Por otro lado, es posible estimar el PIB por habitante europeo para los siglos anteriores a 1500 suponiendo que los salarios reales en Europa eran una media de los italianos (Florencia) e ingleses (Londres) ${ }^{13}$. Para el siglo XV, se pueden utilizar las cifras de Allen (2000a) sobre la estructura del empleo en Europa en 1400. Para el caso holandés, además, he completado la serie entre 1400 y 1500 con estimaciones propias basadas en Van Bavel y Van Zanden (2004). La evolución del grado de urbanización, tomada de De Vries (1984a, p. 43) y Malanima (1998), es utilizada para estimar la trayectoria de la fuerza de trabajo dedicada a la agricultura entre 1300 y 1400. Para fechas anteriores a 1300 el modelo no puede aplicarse, aunque para el caso inglés podemos incorporar la discusión de Campbell (2000, pp. 406-411) sobre las diferentes estimaciones existentes del PIB por habitante entre 1086 y 1300. Este autor concluye, tras minuciosas comparaciones con sus cálculos del producto agrícola en esos años, que el PIB por habitante probablemente se incrementó entre un 10 y un 20 por 100 en dicho período. En este trabajo he utilizado la cifra más alta, según la cual el PIB por habitante inglés en 1086 equivalía a algo menos del 37 por 100 del nivel de 1800 .

Finalmente, realizo una serie de "adivinoestimaciones" para Europa en el año 1000, bajo los siguientes supuestos: 1) en dicha fecha, el porcentaje de la fuerza de trabajo dedicada a la agricultura representaba entre un 85 y un 95 por 100 del total

13 En 1500, el salario real medio (ponderado por la población) en los nueve países aquí estudiados era sólo un 3 por 100 mayor que en Florencia y Londres (éstos sin ponderar). Para el siglo XV también existen datos de salarios reales en Amberes, pero los resultados finales cambian poco si se incorporan a la estimación. 
(frente al 70 por 100 de 1300); y 2) los salarios reales no eran muy distintos de los de principios del siglo XIV (entre un 25 por 100 por encima y un 25 por 100 por debajo del nivel de 1300) ${ }^{14}$. Estos cálculos arrojan un abanico de PIB por habitante entre el 36 y el 42 por 100 del nivel inglés en 1800, cifra sólo ligeramente superior a la de Campbell para la Inglaterra de 1086 (el valor que considero más adecuado para Europa en el año 1000 es el 38 por 100).

Los resultados se recogen en el Gráfico 6 y en el Cuadro 2. Para obtener una perspectiva más a largo plazo, he añadido las series de Maddison (2001) para los siglos XIX y XX. La conclusión más relevante que puede deducirse de esta aproximación es que el "crecimiento económico moderno", en el sentido "kuznetsiano" de incremento sostenido del PIB por habitante, comenzó en Inglaterra en la primera mitad del siglo XVII ${ }^{15}$. El crecimiento, aunque lento, fue marcadamente continuo y persistente entre los años treinta del siglo XVII y los veinte del XIX (de alrededor del 0,4 por 100 anual per capita). En este último decenio y en el siguiente, se registró una segunda aceleración del crecimiento, tras la cual la tasa de incremento del PIB por habitante fue, de nuevo, prácticamente estacionaria en el largo plazo. El fuerte progreso de Inglaterra durante los siglos XVII y XVIII contrasta con lo que sucedía en el resto de Europa occidental — con la excepción, quizá, de Holanda—, donde el punto de inflexión en el crecimiento económico se produjo después de 1800, probablemente en la segunda o tercera década del siglo XIX.

Volvamos de nuevo al crecimiento en la época medieval: lo más llamativo es, si estas estimaciones son correctas, que la mayoría del crecimiento por habitante habido antes de 1800 se produjo con anterioridad a 1450, fecha tras la cual la economía europea - con la notable excepción de algunas zonas situadas en torno al mar del Norte- estuvo estancada durante cerca de 350 años. Este crecimiento anterior a 1450 parece haber tenido lugar en dos etapas. Primero, la revolución comercial y urbana medieval entre c. 1180 y 1330 se caracterizó por la expansión, tanto del PIB por habitante, como de la población. Durante la segunda fase de crecimiento por habitante, entre 1348 y 1450, las cifras de población, por el contrario, presentan una aguda caída; también el PIB total, pero en menor medida que la población. Parece que el shock de 1348 condujo a Europa —y en particular al sur europeo, la zona que más se había expandido durante los tres siglos anteriores- a una "trampa de equilibrio de un nivel alto" (Elvin, 1973), que perduró hasta finales del siglo XVIII.

14 El crecimiento "adivinoestimado" para el período 1000-1300 sería, por tanto, consecuencia de la disminución de la variable Logparticipación.

15 No estoy de acuerdo con De Vries y Van der Woude (1997) cuando afirman que la economía holandesa fue la "primera economía moderna" (al generar un proceso similar de crecimiento económico), dado que, a la centuria de expansión registrada entre 1580 y 1670, le siguió un siglo y medio de estancamiento. Véase Van Zanden (2002b). 


\section{GRÁFICO 6}

ESTIMACIONES DEL PIB POR HABITANTE DE INGLATERRA, ITALIA Y EUROPA OCCIDENTAL, 1000-2000 (números índice, Inglaterra en 1800=100)

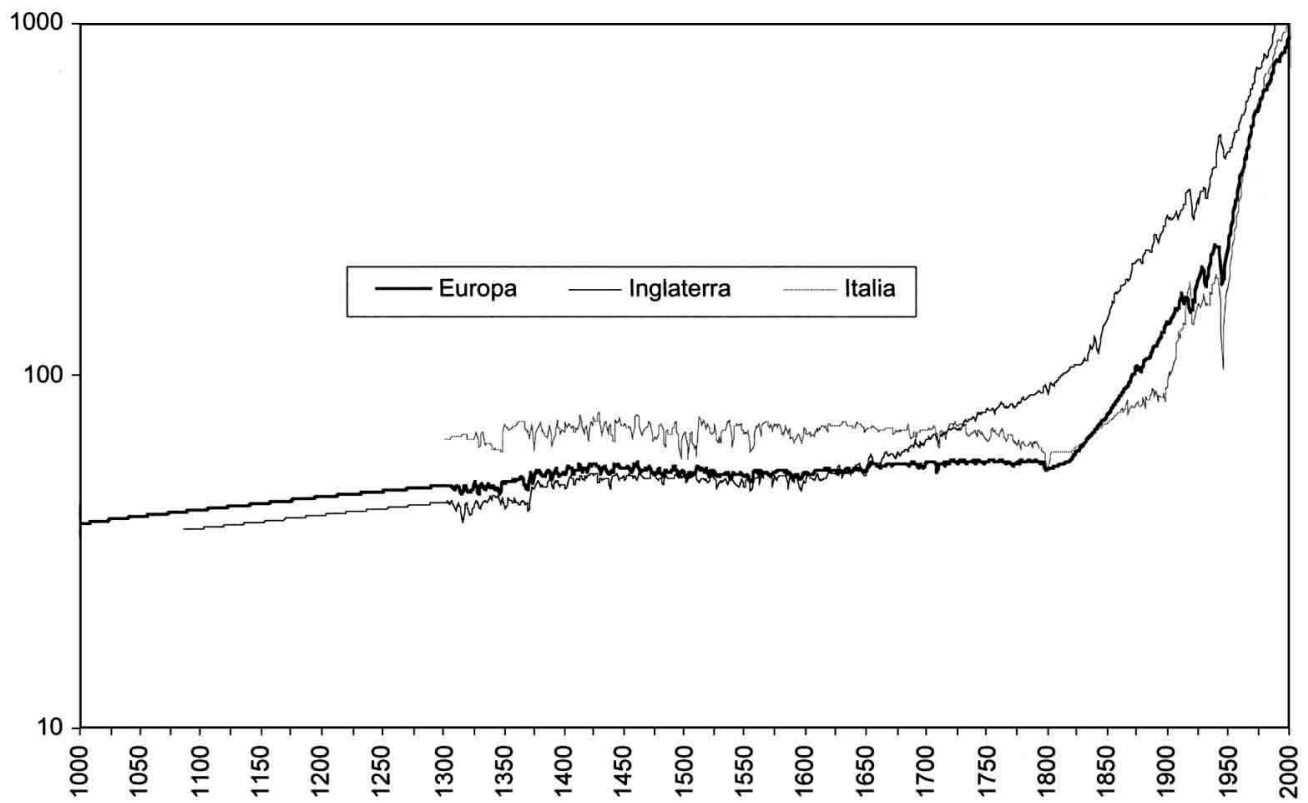

¿Hasta qué punto son válidos estos resultados? Para ser sincero, esperaba que en Europa hubiera tenido lugar un crecimiento mayor entre 1000 y 1800 que el que se deriva de las estimaciones anteriores, según las cuales el PIB por habitante del conjunto europeo "sólo" se incrementó alrededor de un 50 por 100 . Suponiendo que todos los países europeos estuvieran en un rango del 36-40 por 100 en el año 1000 (tomando como base 100 Inglaterra en 1800), sólo dos países destacaron en el largo plazo, Inglaterra y Holanda, cuyos PIB por habitante aumentaron aproximadamente un 150 por 100 antes de 1800 . Italia, por otro lado, presentaba niveles más altos de PIB por habitante durante la Alta y la Baja Edad Media - es posible, incluso, que su nivel de ingreso se doblara entre 1000 y 1400—, pero al menos parte de la diferencia entre este país y los demás probablemente provenía del milenio anterior -ya en el año 1000 Italia se hallaba significativamente más avanzada que el resto de Europa occidental—. El práctico estancamiento del PIB por habitante europeo entre $1450 \mathrm{y}$ 1800 y la correlación negativa que parece existir en la mayoría de los casos entre crecimiento de la población y crecimiento del PIB por habitante, resultan chocantes y 


\section{CUADRO 2}

ESTIMACIONES DEL PIB

(números índice, Inglaterra en 1800=100)

\begin{tabular}{lcccccr}
\hline & $\mathbf{1 3 0 0}$ & $\mathbf{1 4 0 0}$ & $\mathbf{1 5 0 0}$ & $\mathbf{1 6 0 0}$ & $\mathbf{1 7 0 0}$ & $\mathbf{1 8 0 0}$ \\
\hline Inglaterra & 43,8 & 48,5 & 50,7 & 50,6 & 65,8 & $92,4 / 100^{*}$ \\
Holanda & - & - & 77,0 & 84,1 & 97,6 & 97,1 \\
Bélgica & - & 56,1 & 57,1 & 61,2 & 63,1 & 60,4 \\
Italia & 66,4 & 70,8 & 66,6 & 69,1 & 70,3 & 56,7 \\
España & - & - & 49,7 & 46,7 & 45,3 & 41,7 \\
Francia & - & - & 46,7 & 47,7 & 51,3 & 51,1 \\
Alemania & - & - & 52,1 & 47,4 & 51,1 & 51,1 \\
Austria & - & - & 48,8 & 44,6 & 49,7 & 52,8 \\
Polonia & - & - & 40,3 & 43,8 & 45,9 & 48,1 \\
\hline EuRoPA & $\mathbf{4 8 , 3}$ & $\mathbf{5 2 , 1}$ & $\mathbf{5 2 , 1}$ & $\mathbf{5 2 , 0}$ & $\mathbf{5 5 , 5}$ & $\mathbf{5 5 , 4}$ \\
\hline
\end{tabular}

* El modelo "predice" 92,4; el dato real es 100.

requieren ser objeto de nuevas investigaciones. Por ejemplo, ¿debería interpretarse este hecho como evidencia de que existía un techo para la productividad en la Edad Moderna?

Las únicas series más o menos independientes sobre la trayectoria del PIB por habitante de Italia entre 1310 y 1800, con las que comparar las presentadas aquí, son las elaboradas por Paolo Malanima (2003). Estas estimaciones son más detalladas que las publicadas anteriormente por este mismo autor -incluidas en las series de Van Zanden empleadas antes-, pero se basan también en el mismo tipo de información: evolución de los salarios reales, grado de urbanización y cálculos derivados sobre el producto de la agricultura y del resto de la economía. Ambas estimaciones aparecen recogidas en el Gráfico 7. Su comparación muestra que las cifras más recientes de Malanima sobre el derrotero seguido a largo plazo por el PIB por habitante italiano son, incluso, más pesimistas que las mías, y por ello la divergencia se hace mayor según se retrocede en el tiempo. Si las cifras de Malanima son correctas, el PIB por habitante de Italia a principios del siglo XIV (o c. 1420) era casi tan alto como el de Inglaterra en 1800, lo cual es difícil de aceptar. Por tanto, mis estimaciones, en cierta medida más bajas, probablemente se ajustan más a la realidad. No obstante, la trayectoria de ambas series es muy similar. 


\section{GRÁFICO 7}

DOS SERIES DEL PIB POR HABITANTE ITALIANO, 1310-1800

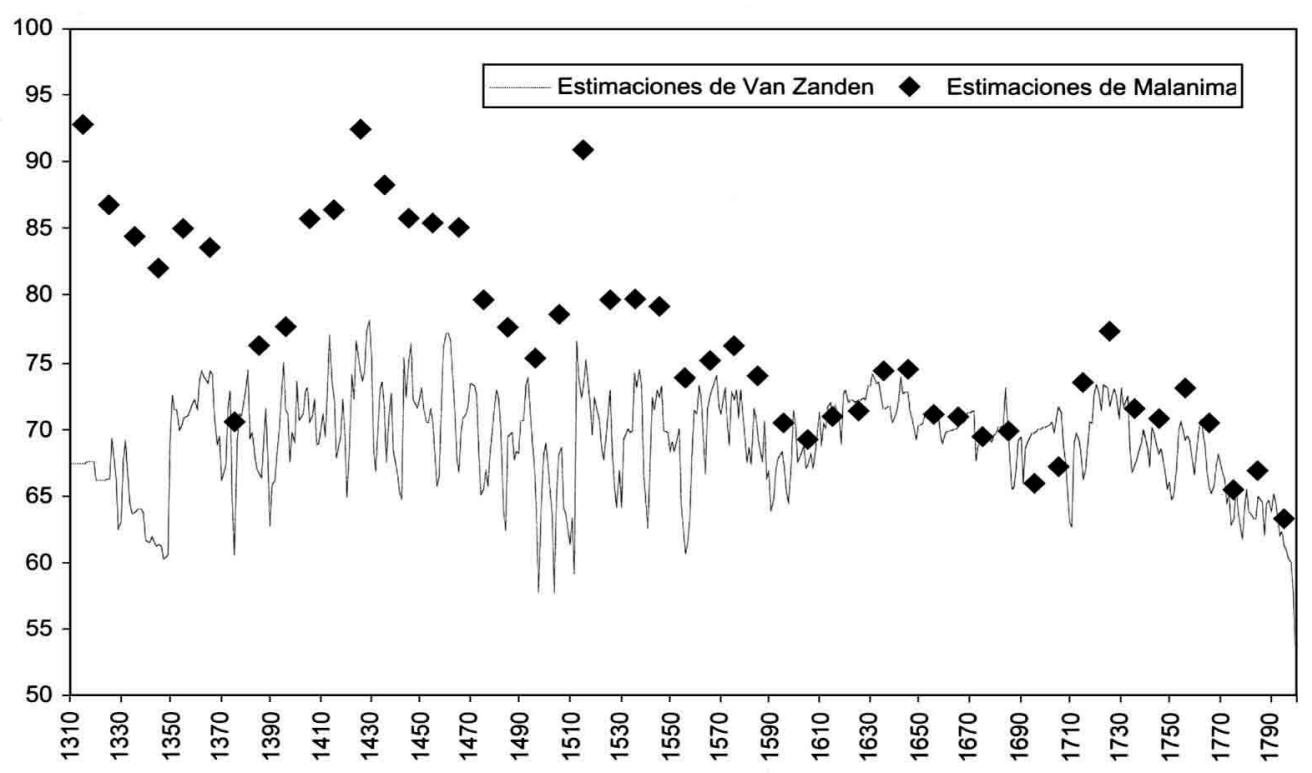

Fuentes: Malanima (2003) y las estimaciones recogidas en el artículo.

Según el sencillo modelo utilizado aquí para estimar la evolución del PIB per capita, las trayectorias de las series anteriores son consecuencia de dos variables: los salarios reales y la participación de la fuerza de trabajo en la agricultura. El práctico estancamiento del PIB por habitante europeo entre 1450 y 1800 es el resultado de una aguda caída de los salarios reales - de alrededor del 50 por 100-, junto con una persistente disminución de la participación de la agricultura en el empleo (aproximadamente, desde el 70 por 100 en 1450 al 57 por 100 en 1800). De forma similar, el aumento de los niveles de ingreso entre 1350 y 1450 es consecuencia del fuerte incremento de los salarios reales en este período, que pone de manifiesto el Gráfico 8. Los niveles de salario real oscilan mucho más que el PIB por habitante —la elasticidad estimada es 0,219-, lo que sugiere que debieron de producirse notables cambios en la distribución del ingreso en los siglos anteriores a 1800. En particular, el ligero crecimiento del PIB por habitante entre $1450 \mathrm{y}$ 1800, vino acompañado de la disminución de los salarios reales, combinación que se habría traducido en un aumento de la desigualdad en el reparto del ingreso ${ }^{16}$. 


\section{GRÁFICO 8}

SALARIOS REALES MEDIOS EN LAS CAPITALES Y PARTICIPACIÓN DE LA AGRICULTURA EN EL EMPLEO EN EUROPA, 1300-1800

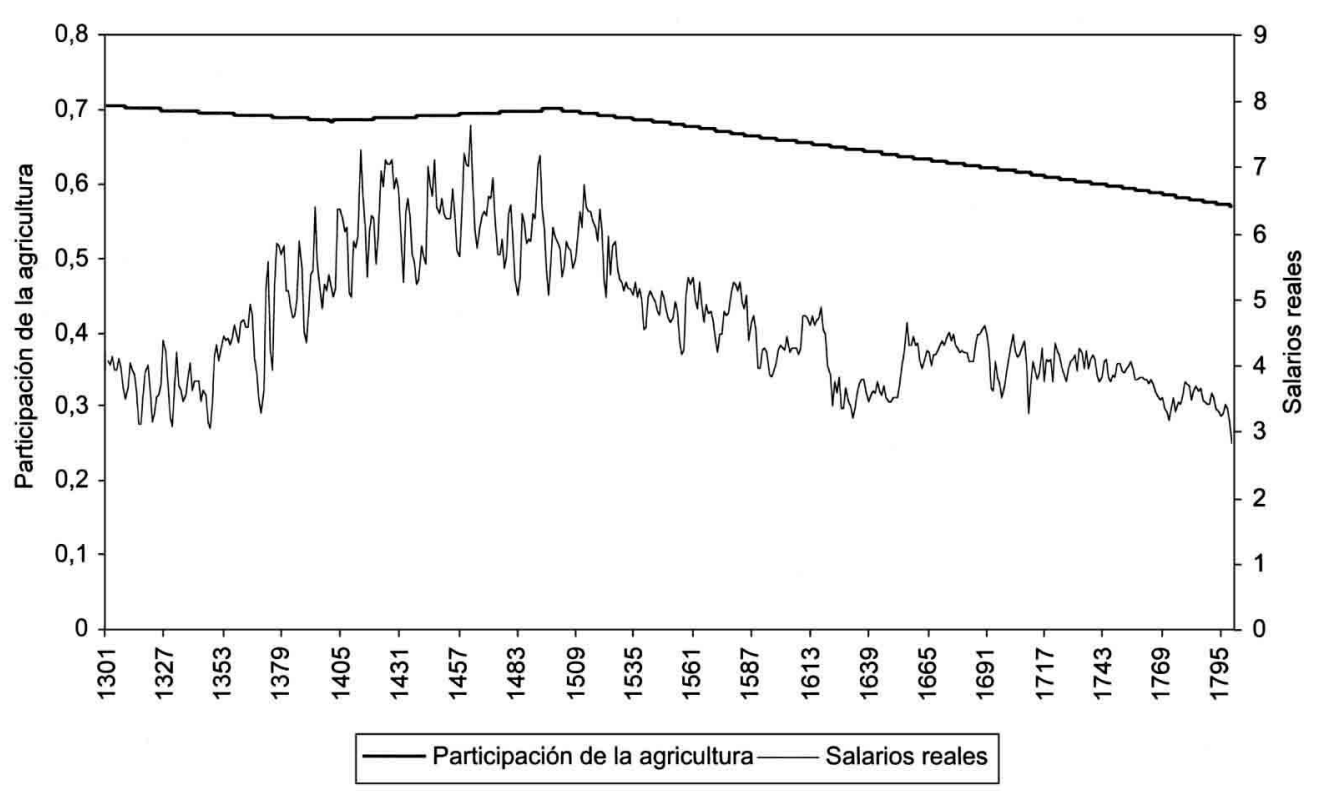

El Gráfico 9 recoge las mismas series para Inglaterra. Este gráfico muestra que la divergencia inglesa respecto de la media europea, desde los años veinte del siglo XVII en adelante, cabe atribuirla a dos procesos interrelacionados: la reducción más rápida de la fuerza de trabajo empleada en la agricultura desde c. 1600 y el fuerte incremento de los salarios reales a partir de alrededor de 1620. Únicamente en Inglaterra, los salarios reales, tras una aguda caída en el transcurso del siglo XVI, "recobraron" a comienzos del Setecientos el máximo de finales de la Edad Media. La divergencia de Holanda durante su "Edad de Oro" puede achacarse a cambios similares; en su caso, la brusca caída de la participación de la agricultura en el empleo tuvo un impacto mayor que el incremento de los salarios reales ${ }^{17}$. no agrícolas. Esto supondrá también una oportunidad para cotejar de un modo más detallado la validez de estas estimaciones. 
GRÁFICO 9

SALARIOS REALES Y PARTICIPACIÓN DE LA AGRICULTURA EN EL EMPLEO

EN INGLATERRA, 1300-1800

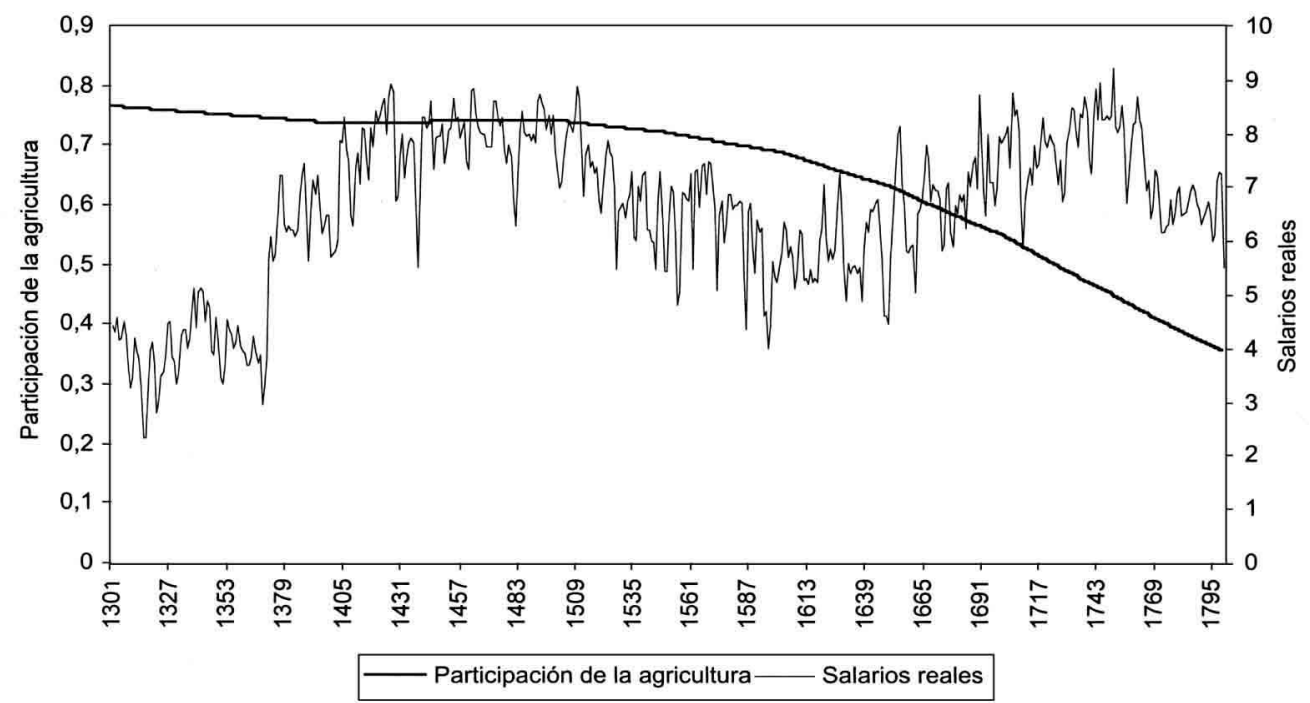

\section{La comparación con China}

Como he indicado en la introducción, una de las razones por las que Maddison supone un relativamente rápido crecimiento económico europeo entre los años 1000 y 1800 se deriva de la comparación con China. Pocos investigadores se mostrarían en desacuerdo con su hipótesis de que, en torno al año 1000, China estaba más desarrollada que Europa, y que, por tanto, su PIB por habitante era mayor. En su estudio sobre el progreso económico chino en el largo plazo, Maddison incluye un estado de la cuestión sobre este punto (Maddison, 1998, pp. 19-38). Para principios del siglo XIX, sin embargo, Maddison calcula que los niveles de ingreso en dicho país eran sólo un tercio de los británicos, y alrededor de la mitad del promedio europeo. Esta diferencia no es fruto, en su opinión, de una caída en los niveles de ingreso chinos. La conclusión, por tanto, es obvia: Europa tuvo que haber crecido muy velozmente entre 1000 y 1800 para que, hacia 1820, la brecha alcanzara semejante magnitud. Así pues, si se aceptan como válidas las estimaciones recogidas en este artículo, que arrojan para Europa unas tasas de crecimiento sustancialmente menores, el interrogante sobre el desarrollo relativo de ambas zonas vuelve a plantearse y ha de volver a analizarse.

El nivel relativo de ingreso y de desarrollo de la economía china en la Edad Moderna ha sido objeto, recientemente, de numerosas investigaciones y de un mayor debate. Li Bozhong (1998), K. Pomeranz (2000) y R. B. Wong (1997) han argumentado que algunas zonas de China —en especial, el delta del Yangtsé- se desarrollaron de modo mucho 
más intenso en los siglos anteriores a 1800 de lo que habíamos venido suponiendo. Tradicionalmente, la evolución a largo plazo de la economía china entre la dinastía Sung (960-1275) y el siglo XIX, había sido caracterizada como un proceso de involución —es decir, de disminución de los niveles de ingreso, como consecuencia del crecimiento de la población; véase Huang (1990)_, o como una "trampa de equilibrio alto", en referencia a que el ingreso se mantuvo más o menos igual (Elvin, 1973). Además, Pomeranz en particular ha mantenido que, en términos de niveles de ingreso, China habría estado a la par con Europa en 1750, y que la región del delta del Yangtsé habría sido tan próspera como las partes más avanzadas de Europa occidental (Inglaterra y Holanda). Maddison (2003, pp. 249-251), no obstante, rechaza estas afirmaciones. Este autor estima sus cifras de 1820 comparando las paridades del poder adquisitivo de los años noventa del siglo XX, en combinación con series de PIB por habitante para el período 1820-1990. Este método está sujeto a numerosas críticas (como probablemente cualquier otro utilizado para el mismo propósito). Uno de los problemas es la escasa calidad de las cuentas nacionales históricas chinas. Para el período anterior a 1912 se carece de estudios fiables, y la evidencia para el crecimiento atribuido a 1912-1949, así como para fechas posteriores a 1949, es muy precaria (Maddison, 1998). Las discontinuidades para algunas fechas en las series disponibles — a causa de la II Guerra Mundial y del acceso al poder de los comunistas en 1949_, y las pobres estadísticas oficiales para el lapso posterior a 1949, son razones importantes para dudar de la validez de las series utilizadas a la hora de enlazar las estimaciones de 1990 con las de inicios del siglo XIX.

Una de las comparaciones que pueden realizarse fácilmente es a través de otro país para el que existan estimaciones del PIB más fiables. En un detallado análisis de los niveles de ingreso y de la paridad del poder adquisitivo en Java y Holanda durante la primera mitad del siglo XIX, concluí que las estimaciones de Maddison sobre la brecha detectada en el ingreso entre ambas zonas en 1820 podían considerarse más o menos correctas: el PIB por habitante holandés equivalía a unas tres veces el javanés (Van Zanden, 2003). Maddison calcula, no obstante, que el PIB por habitante chino en 1820 era menor que el indonesio, algo que es poco probable. Para el caso de Java (y el resto del Sureste de Asia), China era claramente la economía más avanzada, desde la cual se podía importar espíritu empresarial, mano de obra cualificada, tecnología y capital, así como productos manufacturados. Uno esperaría, por tanto, que el PIB por habitante chino fuera considerablemente mayor que el de Java.

Una forma de abordar esta cuestión es tratar de ajustar el caso de China (o de algunas partes del país) al "modelo" construido para Europa. R. Allen (2000b) ha efectuado cálculos de los salarios reales de los trabajadores agrícolas ingleses hacia 1750, señalando que los salarios chinos representaban el 82 por 100 de la media inglesa. Además, existen diversas estimaciones de la estructura del PIB y / o de la fuerza de trabajo. Para principios del siglo XIX, Rozman (1973) calculó que la agricultura proporcionaba el 70 por 100 del PIB, cifra que cabe tomar como una estimación aproximada para el conjunto de China. Para el delta del Yangtsé, la zona más desarrollada y próspera del imperio, pueden reali- 
zarse evaluaciones más detalladas. J. Goldstone (2003) utiliza las pormenorizadas estimaciones de Li Bozhong (1998) sobre el tamaño y estructura de la economía rural en Jiangnan (parte del delta del Yangtsé), para elaborar un conjunto de series de niveles de ingreso de la población agrícola y protoindustrial de dicha zona en 1620 y 1750. Este estudio, sin embargo, no recoge cifras de ingreso de la población rural no agrícola —estimada por el autor en un 10 por 100 de la población rural—, ni de la población urbana —el 15 por 100 en 1620, y el 20 por 100 en 1750 de la población total de la zona-. Si suponemos que esta población no agrícola poseía un nivel de ingreso que era de dos a tres veces el de los campesinos — proporción que parece razonable-, es posible confeccionar estimaciones de la estructura del PIB y del empleo en Jiangnan. Las diferencias entre tales estimaciones para 1620 y 1750 son bastante pequeñas; en ambas fechas, la agricultura representaba — dependiendo del supuesto que se realice acerca del nivel de ingreso relativo de la población no agrícola- entre el 55 y el 65 por 100 del PIB. La participación de la agricultura en el empleo total era incluso menor, aproximadamente un 51 por 100 en 1750 y un 54 por 100 en 1620. De lo que se deduce que la productividad del trabajo en la agricultura era — marginalmente- mayor que en la industria y los servicios ${ }^{18}$.

La incorporación de estas estimaciones al modelo establecido para el caso europeo proporciona los siguientes resultados (en índices con base 100 en el nivel de Inglaterra en 1800): el PIB por habitante chino en 1750/1800 representaría el 53 por 100 del nivel de referencia, suponiendo un salario real equivalente al 82 por 100 del inglés y una participación de la agricultura en el empleo total del 70 por 100. Esta cifra es similar a la europea en 1750 (56 por 100), y un 35 por 100 inferior a la inglesa para ese mismo año (80 por 100). Jiangnan en 1750 (con un salario real del 82 por 100 del inglés, y un 51 por 100 del empleo en la agricultura) tendría un índice de 68, cifra superior a la media europea, y tan sólo un 15 por 100 menor que la inglesa por esas mismas fechas. Este resultado se encuentra entre las interpretaciones de Pomeranz y de Maddison a este respecto.

El problema para efectuar comparaciones más directas entre China y Europa, utilizando el método establecido de calcular niveles de ingreso y paridades del poder adquisitivo, es la falta de información sobre precios en China. Una manera de eludirlo consiste en emplear el precio del arroz como base para realizar las comparaciones. Las estimaciones para Jiangnan derivadas de los trabajos de Li Bozhong y Goldstone implican que el PIB por habitante de esta zona equivalía a $650-790 \mathrm{~kg}$. de arroz en 1750 , siendo ligeramente mayor, 680-800 kg., en 1620 (de nuevo, en función de la estimación del nivel relativo de ingreso y de la población no agrícola). El PIB por habitante de Java entre 1815 y 1835 era, en promedio, el equivalente a $490 \mathrm{~kg}$. de arroz, lo que proporciona un indicador

18 Esto es consecuencia directa de las estimaciones de Li Bozhong y Goldstone, que consideran un día de trabajo femenino como equivalente a medio día masculino. La relativamente alta productividad de la agricultura, tanto en 1620 como en 1750, ayuda a comprender la trayectoria de desarrollo de China en ese período, en especial su lenta tasa de cambio estructural, dado que ello implica que los incentivos al éxodo de trabajadores de la agricultura a la industria y a los servicios eran escasos. 
de la magnitud de la brecha entre la "subdesarrollada" Java y el "desarrollado" delta del Yangtsé. Midiendo en términos de cesta de la compra, probablemente las diferencias fuesen más abultadas, ya que China exportaba productos industriales y servicios, mientras que Java sólo vendía arroz al exterior; sin embargo, no disponemos de información para comprobar esta hipótesis. Dado que el PIB por habitante de Java en 1820 equivalía, según Van Zanden (2003), a cerca de la mitad del nivel europeo, las diferencias estimadas entre Europa y Jiangnan serían bastante pequeñas —o incluso no existirían-. Lo cual sugiere, de nuevo, que la cifra de Maddison del PIB por habitante de China hacia 1820, menor que la de Indonesia, podría ser excesivamente baja.

Distintas aproximaciones, por tanto, nos llevan a la conclusión de que el nivel relativo de PIB por habitante de China en el siglo XVIII era, quizá, similar o ligeramente menor al de Europa occidental (de la Europa occidental que se considera en este trabajo; si incluimos el resto de Europa central y oriental esta ratio aumentaría). Y el PIB por habitante en la parte más desarrollada de China, Jiangnan, representaría entre el 80 y el 90 por 100 de los de Inglaterra y Holanda. ¿Soluciona esto el problema de China? Supongamos por un momento que el nivel relativo de China, en 1750, fue efectivamente el 50-55 por 100 del inglés de 1800, y que hubiese permanecido constante entre los años 1000 y 1800. De acuerdo con las estimaciones aquí recogidas, Europa habría estado entonces a la par de China durante buena parte de la Edad Moderna; en realidad, desde el siglo XV hasta la aceleración del crecimiento en los años veinte y treinta del Ochocientos (véase el Cuadro 2). Este escenario sería consistente con la interpretación de Pomeranz (2000) sobre la "Gran Divergencia" (en el año 1000, el PIB por habitante chino habría sido, aproximadamente, un 50 por 100 mayor que el europeo) ${ }^{19}$.

Afortunadamente, tales cuestiones no tienen que resolverse en este trabajo. Mi única intención ha sido demostrar que, como probablemente Maddison ha infravalorado el PIB por habitante chino en torno a 1800 con relación a los niveles europeos, puede ser compatible un relativamente lento crecimiento del PIB por habitante europeo con un intercambio de posiciones entre ambas zonas, en algún momento situado entre comienzos del siglo XI y finales del XVIII. En otras palabras, para resolver este problema no hay que suponer que el PIB por habitante europeo se triplicó en esos ocho siglos.

19 El hecho de que el PIB por habitante chino fuera constante no es, sin embargo, evidente. La interpretación del crecimiento económico de Jiangnan entre 1620 y 1750 aquí presentada, sugiere que los niveles de ingreso podrían haber caído en cierta medida, incluso en esta zona que era la más dinámica de China. Existe alguna evidencia al respecto para el conjunto del país: el grado de urbanización posiblemente se redujo entre el siglo XIII y el XIX —así lo indican Elvin (1973, pp. 177-178) y Chao (1986)—. Esta trayectoria no ha sido tenida en cuenta por Maddison, quien confía en los resultados, muy preliminares, de Rozman. Otra vez el delta del Yangtsé sería la excepción. Un caso paralelo que nos viene a la cabeza es el estancamiento y la progresiva caída a largo plazo de las economías castellana e italiana en ese mismo período, que también vinieron acompañadas de la disminución de las ratios de urbanización después de 1300 (Italia) o de 1560 (Castilla) [Malanima (1998), Reher (1990)]. 


\section{Conclusiones}

Este artículo ha sido crítico con algunos de los resultados del ambicioso proyecto de Angus Maddison, encaminado a estimar la evolución del PIB por habitante en el pasado milenio. Dicha crítica no es fruto de una falta de respeto hacia su trabajo. De hecho, en mi opinión, su proyecto es una de las empresas más interesantes y ambiciosas de las emprendidas recientemente por los historiadores económicos, la culminación de una larga dedicación a la contabilidad nacional histórica. Uno de los propósitos de su trabajo es ir más allá de las estimaciones efectuadas por otros estudiosos que, con más cautela, han investigado sobre países concretos y para fechas más recientes. Con la construcción de nuevas estimaciones para territorios poco explorados, Maddison ha desafiado con frecuencia las visiones tradicionales y ha forzado a otros colegas a hacer avanzar la investigación a partir de sus resultados preliminares. En mi caso, su atrevida síntesis, recogida en The World Economy. A Millennial Perspective, me estimuló - como anteriormente a Giovanni Federico- a repensar lo que yo creía que había sucedido en Europa entre 1000 y 1800. Este artículo, por tanto, se enmarca en la gran estrategia "maddisoniana" de mejorar sus estimaciones, y las nuestras, del crecimiento económico en el pasado.

La principal conclusión del presente artículo, en la que coincido con Giovanni Federico, es que el crecimiento europeo entre 1000 - o 1500 - y 1820 tuvo que haber sido mucho menor que el sugerido por Maddison. Para sustentarla, he aportado dos razones: la relación existente entre crecimiento y cambio estructural en 1820, y las estimaciones elaboradas por varios historiadores económicos reconocidos (Malanima, Yun, Krantz, Carreras) sobre el crecimiento de determinadas zonas y países. Además, presento una forma de calcular el crecimiento europeo antes de 1800, a partir de la información disponible sobre el cambio económico a largo plazo (estimaciones de salarios reales y de la estructura del empleo). Ello permite explorar, aunque de forma preliminar, el crecimiento económico habido entre comienzos del siglo XI y finales del XVIII. El modelo "predice" la trayectoria del crecimiento de la mayoría de los países analizados — en particular, de Italia, España, Holanda e Inglaterra - de modo bastante "correcto"; es decir, de forma consistente con las interpretaciones mayoritariamente aceptadas, lo que no es sorprendente dado que el modelo se basa en una síntesis cuantitativa de las mismas. La imagen general que resulta es la de un leve crecimiento en Europa entre c. 1000 y 1450, seguido de un práctico estancamiento durante tres siglos y medio. En promedio, el PIB europeo por habitante se habría incrementado en torno al 50 por 100 entre 1000 y 1800, porcentaje probablemente inferior al esperado por la literatura - pero el propósito de experimentos como éste es, precisamente, comprobar y/o modificar visiones establecidas-. Algunas zonas del sur de Europa, Italia en particular, registraron un crecimiento relativamente rápido durante los tres o cuatro primeros siglos del milenio, que se tradujo probablemente en la duplicación de los niveles de ingreso. No obstante, después de 1500, tanto el PIB por habitante de Italia, como el de España, disminuyeron a largo plazo. Holanda e Inglaterra son los dos casos de mayor éxito, con un crecimiento por habitante del 150 por 100, quizá, entre 1000 
y 1800. Este ensayo también permite llegar a la conclusión de que el "crecimiento económico moderno" se inició en la primera mitad del siglo XVII, cuando - tras su estancamiento en la centuria anterior-, el PIB por habitante inglés comenzó a crecer, lenta pero persistentemente. Por último, argumento que estas estimaciones son válidas, también, a la hora de efectuar una comparación con la evolución en el largo plazo de la economía china, pero, evidentemente, aún queda mucho por hacer antes de que en semejante ámbito podamos apoyarnos en unos cimientos suficientemente sólidos y seguros.

\section{APÉNDICE. Un modelo alternativo}

Un sugerente modelo alternativo puede probarse añadiendo variables dummiestiempo para todos los años excepto 1380-1450 (los primeros para los cuales existen algunas estimaciones de PIB por habitante). Los resultados son los siguientes:

\begin{tabular}{|c|c|c|c|c|}
\hline & Coeficiente & Error estándar & Valor de $\mathrm{t}$ & Prob. de $t$ \\
\hline Logparticipación & $-0,7597$ & 0,2053 & $-3,70$ & 0,002 \\
\hline Logsalariosreales & 0,2261 & 0,1490 & 1,52 & 0,146 \\
\hline Holanda & 0,2036 & 0,0524 & 3,89 & 0,001 \\
\hline Bélgica & $-0,0962$ & 0,0544 & $-1,77$ & 0,094 \\
\hline Italia & 0,2632 & 0,1023 & 2,57 & 0,019 \\
\hline España & $-0,1426$ & 0,0709 & $-2,01$ & 0,060 \\
\hline Polonia & $-0,1804$ & 0,0918 & $-1,97$ & 0,065 \\
\hline Constante & 3,4154 & 0,2934 & 11,60 & 0,000 \\
\hline T1500 & $-0,1487$ & 0,0569 & $-2,61$ & 0,018 \\
\hline T1570 & $-0,0263$ & 0,1345 & $-0,20$ & 0,847 \\
\hline T1600 & $-0,1884$ & 0,0857 & $-2,20$ & 0,041 \\
\hline T1650 & $-0,0837$ & 0,1495 & $-0,56$ & 0,582 \\
\hline T1700 & $-0,1413$ & 0,0997 & $-1,42$ & 0,173 \\
\hline T1750 & $-0,1719$ & 0,1019 & $-1,69$ & 0,109 \\
\hline \multirow[t]{3}{*}{ T1800 } & $-0,0677$ & 0,1689 & $-0,40$ & 0,693 \\
\hline & $R^{2} 0,8733$ & RSS 0,3625 & TSS 2,86 & \\
\hline & \multicolumn{3}{|c|}{$\mathrm{N}^{\circ}$ de observaciones: 33} & \\
\hline
\end{tabular}

Añadir variables dummies-tiempo no supone grandes cambios en el modelo; los coeficientes de las principales variables explicativas son muy similares a los obtenidos sin incluir dichas variables. Sí es sorprendente, en cambio, que todas las variables dummies tengan signo negativo. Esto significa que el PIB por habitante en 13801450 fue mayor que el "predicho" por el modelo o, alternativamente, que entre 1500 y 1800 fue menor de lo esperado de acuerdo con el mismo. 


\section{Bibliografía}

ALLEN, Robert C. (2000a): "Economic structure and agricultural productivity in Europe, 1300-1800", European Review of Economic History, 4, pp. 1-27.

- (2000b): "Real wages in Europe and Asia: a first look at the long term patterns", comunicación presentada al congreso "New evidence of standard of living in preindustrial Europe and Asia", Arild, Sweden, 1-5 agosto.

-(2001): "The great divergence in European wages and prices", Explorations in Economic History, 38, pp. 411-447.

-(2003): "Progress and Poverty in early modern Europe", Economic History Review, LVI, 3, pp. 403-443.

BAVEL, Bas van, y ZANDEN, Jan L. van (2004): “The Jump-start of the Holland economy during the late Medieval crisis, c. 1350-c. 1500", Economic History Review, LVII, pp. 403-443.

BLOMME, Jan, y WEE, Herman van der (1994): “The Belgian economy in a LongTerm perspective", en MADDISON, Angus, y WEE, Herman van der (coords.), Economic growth and structural change. Comparative approaches over the long run on the basis of reconstructed national accounts. XI Congreso Internacional de Historia Económica, Milán, Sesión B13.

BURGER, Ary (1996): “Dutch patterns of development: economic growth and structural change in the Netherlands, 1800-1910", Economic and Social History in the Netherlands, 7, pp. 161-181.

CAMPBELL, Bruce M. S. (2000): English seigniorial agriculture, 1250-1450, Cambridge, Cambridge University Press.

CARRERAS, Albert (2003): “Modern Spain”, en MOKYR, Joel et al. (eds.), The Oxford Encyclopedia of Economic History, Oxford U. P., Vol. 4, pp. 546-553.

CHAO, Kang (1986): Man and land in Chinese history, Stanford, Stanford University Press.

CHENERY, Hollis B., y SYRQUIN, Moises (1975): Patterns of development, 1950-1970, Londres, Oxford University Press.

CLARK, Colin G. (1940): The conditions of economic progress, Londres, Macmillan.

CRAFTS, Nicholas F. R. (1985): British Economic Growth during the Industrial Revolution, Oxford, Clarendon Press.

ELVIN, Mark (1973): The pattern of the Chinese past, Londres, Methuen.

FEDERICO, Giovanni (2002): "The world economy 0-2000 AD: a review article", European Review of Economic History, 6, pp.111-121.

GOLDSTONE, Jack (2003): "Feeding the people, starving the state: China's agricultural revolution of the $17^{\text {th }}$ and $18^{\text {th }}$ centuries", comunicación presentada al congreso de la Global Economic History Network, Londres, 18-20 septiembre. 
HOFFMAN, Philip T., JACKS, David S., LEVIN, Patricia A., y LINDERT, Peter H. (2002): "Real Inequality in Europe since 1500", Journal of Economic History, 62 (2), p. 322-355.

KRANTZ, Olle (2004): "An estimate of Swedish GDP in 1571", en HEIKKINEN, Sakari y ZANDEN, Jan L. van (eds.), The experience of economic growth, Aksant, Amsterdam.

KUZNETS, Simon (1966): Modern economic growth. Rate, structure and spread. New Haven, Yale University Press.

LI BOZHONG (1998): Agricultural development in Jiangnan, 1620-1850, New York, St. Martin's Press.

MADDISON, Angus (1995): Monitoring the World Economy, 1820-1992, OECD, París.

-(1998): Chinese economic performance in the long run, OECD, París.

-(2001): The world economy: a millennial perspective, OECD, París.

-(2003): The world economy: historical statistics, OECD, París.

MALANIMA, Paolo (1994): “Italian Economic Performance, 1600-1800”, en MADDISON, Angus, y WEE, Herman van der (coords.), Economic growth and structural change. Comparative approaches over the long run on the basis of reconstructed national accounts. XI Congreso Internacional de Historia Económica, Milán, Sesión B13.

-(1998): "Italian cities 1300-1800. A quantitative approach", Rivista di Storia Economi-ca, XIV, 2, pp. 91-126.

-(2003): “Measuring the Italian economy, 1300-1861", Rivista di Storia Economica, XIX, pp. 265-297.

OVERTON, Mark, y CAMPBELL, Bruce M.L. (1997): “Production et productivité dans l'agriculture anglaise, 1086-1871", Histoire et Mésure, 11, pp. 255-297.

POMERANZ, Kenneth (2000): The Great Divergence. China, Europe and the Making of the Modern World Economy, Princeton, Princeton University Press.

REHER, David S. (1990): Town and country in pre-industrial Spain: Cuenca 1550-1870, Cambridge, Cambridge University Press.

ROZMAN, Gilbert (1973): Urban networks in Ch'ing China and Tokugawa Japan, Princeton, Princeton University Press.

SNOOKS, Graeme D. (1990): "Economic Growth during the Last Millennium: A Quantitative Perspective for the British Industrial Revolution", Working Paper in Economic History, 140, Australian National University.

-(1994): "Great waves of economic change", en SNOOKS G. D. (ed.), Was the Industrial Revolution necessary?, Londres, Routledge, pp.43-79.

TOPOLSKI, Jerzy, y WYCZANSKI, Andrzej (1982): “Les fluctuations de la production agricole en Pologne XVIe-XVIIIe siècles", en GOY, Joseph, y LE ROY LADURIE, Emmanuele (eds.), Prestations paysannes, dîmes, rente foncière et mouvement de la production agricole à l'époque préindustrielle, I, Paris, Edition de l’EHESS. 
VRIES, Jan de (1984a): European urbanization 1500-1800, Londres, Methuen.

-(1984b): "The decline and rise of the Dutch economy 1675-1900", en SAXONHOUSE, Gary, y WRIGHT, Gavin (eds.), Forms and methods in economic history: essays in honour of William N. Parker, Greenwich, JAI Press, pp. 149-189.

VRIES, Jan de y WOUDE, Ad van der (1997): The first modern economy: success, failure, and perseverance of the Dutch economy, 1500-1815, Cambridge, Cambridge University Press.

WONG, Roy Bin (1997): China transformed: historical change and the limits of European experience, Ithaca, Cornell University Press.

WRIGLEY, Edward A. (2000): “The Divergence of England: the growth of the English economy in the seventeenth and eighteenth centuries", Transactions of the Royal Historical Society, 6th series, 10, pp.117-141.

YUN, Bartolomé (1994): "Proposals to Quantify Long Term Performance in the Kingdom of Castile, 1550-1800", MADDISON, Angus, y WEE, Herman van der (coords.), Economic growth and structural change. Comparative approaches over the long run on the basis of reconstructed national accounts. XI Congreso Internacional de Historia Económica, Milán, Sesión B13.

ZANDEN, Jan L. van (1987): “De economie van Holland in de periode 1650-1805: groei of achteruitgang?", Bijdragen en mededelingen betreffende de geschiedenis der Nederlanden, 102, pp. 562-609.

-(1992): "Economic growth in the Golden Age", Economic and social history in the Netherlands, IV, pp. 5-26.

-(1993): “The Dutch Economy in the Very Long Run”, en SZIRMAI, Adam (ed.), Explaining Economic Growth, Amsterdam, North-Holland, pp. 267-284.

-(1995): "Tracing the beginning of the Kuznets curve: Western Europe during the early modern period", Economic History Review, XLVIII, pp. 643-664.

-(2001): "Early modern economic growth: a survey of the European economy 1500-1800", en PRAK, M. (ed.), Early Modern Capitalism, Londres, Routledge, pp. 69-87.

- (2002a): "Taking the measure of the early modern economy. Historical national accounts for Holland in 1510/14", European Review of Economic History, 6, pp. 3-36.

-(2002b): "The revolt of the early modernists: an assessment", Economic History Review, LV, pp. 595-623

-(2003): "Rich and poor before the Industrial Revolution: a comparison between Java and the Netherlands at the beginning of the 19th century", Explorations in Economic History, 40, pp. 1-23.

ZANDEN, Jan L. van, y RIEL, Arthur van (2004): The structures of inheritance. State, economy and institutional change in the Netherlands, 1780-1914, Princeton, Princeton University Press. 